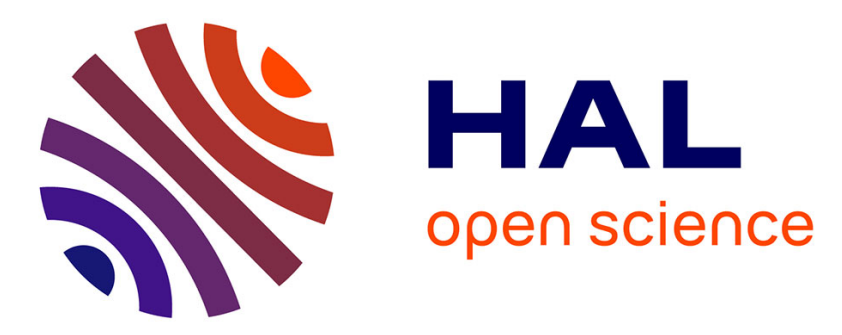

\title{
Human capital background and the educational attainment of the second-generation immigrants in France
}

Manon Domingues dos Santos, François-Charles Wolff

\section{- To cite this version:}

Manon Domingues dos Santos, François-Charles Wolff. Human capital background and the educational attainment of the second-generation immigrants in France. 2009. hal-00417879

\author{
HAL Id: hal-00417879 \\ https://hal.science/hal-00417879
}

Preprint submitted on 17 Sep 2009

HAL is a multi-disciplinary open access archive for the deposit and dissemination of scientific research documents, whether they are published or not. The documents may come from teaching and research institutions in France or abroad, or from public or private research centers.
L'archive ouverte pluridisciplinaire HAL, est destinée au dépôt et à la diffusion de documents scientifiques de niveau recherche, publiés ou non, émanant des établissements d'enseignement et de recherche français ou étrangers, des laboratoires publics ou privés. 
EA 4272

\section{Human capital background and the educational attainment of the second-generation immigrants in France}

Manon Domingues Dos Santos $\left({ }^{*}\right)$
François-Charles Wolff $\left(^{* *}\right)$

$2009 / 01$

$\left.{ }^{*}\right)$ Corresponding author. OEP, University Paris-Est Marne-la-Vallée and CREST, INSEE, France

$\left({ }^{* *}\right)$ LEMNA, Université de Nantes ; CNAV and INED, France

July 2009

Laboratoire d'Economie et de Management Nantes-Atlantique

Université de Nantes

Chemin de la Censive du Tertre - BP 52231

44322 Nantes cedex 3 - France

www.univ-nantes.fr/iemn-iae/recherche 


\title{
Human capital background and the educational attainment of the second-generation immigrants in France ${ }^{\#}$
}

\author{
Manon Domingues Dos Santos * François-Charles Wolff ${ }^{* *}$
}

July 2009

\begin{abstract}
In this paper, we study the impact of the human capital background on ethnic educational gaps between second-generation immigrants in France. First, we show that the skill of immigrants explains the main part of the ethnic educational gap between their children. More precisely, if the education of immigrants has a predominant impact on the educational attainment of their children, their assimilation degree, essentially captured by their French fluency or their length of stay in France, also contributes to explain ethnic educational gaps. Secondly, we show that the impact of the immigrants' education on the educational attainment of their children depends on their country of origin, their place of schooling as well as their French proficiency.
\end{abstract}

Keywords: Immigration, second generation, educational attainment

JEL Classification: I21, J15, J24, J61

\footnotetext{
\# We would like to thank two anonymous referees for their very helpful comments and suggestions. We are also indebted to Pierre Cahuc, Arnaud Chevalier, Francis Kramarz and participants at the TEMA seminar (University Paris 1), the Crest seminar (INSEE), the Journées de Microéconomie Appliquée (Fribourg), the Annual Conference of the European Society for Population Economics (Chicago) and the Annual Conference of the European Association of Labour Economics (Oslo) for useful comments. The usual disclaimer applies.

* Corresponding author. OEP, University Paris-Est Marne-la-Vallée and CREST, INSEE, France.

Email : manondds@ensae.fr http://www.crest.fr/pageperso/manondds/manondds.htm

${ }^{* *}$ LEMNA, Université de Nantes ; CNAV and INED, France.

Email: wolff@sc-eco.univ-nantes.fr http://www.sc-eco.univ-nantes.fr/ fcwolff
} 


\section{Introduction}

In France, $42 \%$ of the young men and $27 \%$ of the young women whose parents are Maghrebians leave school without any diploma. Among the children whose parents are natives or Southern Europeans, this proportion is two times lower for the men and nearly three times lower for the women (Lainé and Okba, 2005). In many countries, significant differences are also observed between the educational achievements of children from different origins (OECD, 2006). What can explain such inequalities? As emphasized in the seminal paper of Chiswick (1988), three main hypotheses may be relevant to explain why ethnic groups differ in their level of educational attainment.

First, some communities are likely to have a greater preference for schooling, which may be induced by cultural, religious, historical or other factors. This particular taste for schooling can lead members of these communities to invest more in their schooling and in the schooling of their descendants. Secondly, ethnic differences in educational attainment may arise from discrimination in schooling or in the labour market. During their studies, children from some communities may be discriminated with regard to access to schooling, quality of schooling, grade retention or tracking decisions (Losen and Orfield, 2002). During their working life, they can face less favourable job conditions. As the return of their investment in human capital is lower, they would then be less motivated to invest in skill (Coate and Loury, 1993). Thirdly, some ethnic communities can be over-represented in the most disadvantaged socio-economic backgrounds with respect to formal educational achievement. According to the theory of human capital (Becker and Tomes, 1986), immigrants of these communities would then provide less human and financial capital for the education of their children.

Do we have to promote special educational programs in favour of some secondgeneration youths? Do we have to assist immigrants themselves in their educative mission? Are anti-discriminatory policies which encourage anonymous applications able to narrow the educational gaps? To evaluate the relative efficiency of such policies, it is necessary to rigorously identify the determinants of the educational attainment gaps. The present paper intends to contribute to this task in analysing how differences among immigrant communities with respect to their human capital background are likely to explain the educational attainments gaps among their descendants. For that purpose, we use a detailed data set collected on immigrants aged between 45 and 70 living in France in 2003.

Specifically, we extend in two ways the growing literature which intends to understand the role of the family socio-economic backgrounds on the educational attainment of the second generation immigrants. On the one hand, our contribution is the first study 
which analyses this issue on French data. Indeed, the major part of empirical studies is focused on Anglo-Saxon countries ${ }^{1}$. It is not obvious that their results can be readily extrapolated to the situation of immigrants in other countries. Notably, institutional differences in immigration policies and education systems between Anglo-Saxon and European countries might affect the educational achievement of children of immigrants.

On the other hand, this paper contributes to better identify the specificities and the impact of the human capital backgrounds of the children of immigrants. More precisely, a unique feature of our original data is to provide a large set of information about the migratory history of the parents of the second-generation immigrants such as their fluency in the host country language, their age at immigration, their length of stay or the place of their studies. Hence, as long as the migration history of immigrants affects their assimilation process, it is also likely to directly influence the educational attainment of their children as well as the ability of immigrants to transfer their skills to them. Since previous studies do not consider these potential interactions, the present contribution intends to put them in evidence.

Our main results are the following. First, we show that the skill of immigrants explains the main part of the ethnic educational gaps between their descendants. More precisely, the educational attainment of immigrants has a predominant impact on the educational attainment of their children. Nevertheless, the assimilation degree of immigrants, essentially captured by their French fluency or their length of stay in their host country, also contributes to explain a part of the ethnic educational gaps between their children. Second, we show that the return of the educational attainment of immigrants on the educational attainment of their children depends on their place of origin, their place of schooling as well as their French proficiency. Notably, French proficiency increases the return of education of immigrants.

The remainder of this paper is organized as follows. Section 2 provides a brief introduction to the literature on human capital background and the educational attainment of second-generation immigrants. Section 3 presents the French data, while the econometric strategy, the main results and robustness issues are discussed in Section 4. Finally, Section 5 concludes.

\section{Background on the educational attainment of second-generation immigrants}

According to the Programme for International Students Assessment (OECD, 2006), in many OECD countries the second-generation students - defined as those who are born in the

\footnotetext{
${ }^{1}$ Gang and Zimmermann (2000) on Germany and Van Ours and Veenman (2003) on Netherlands are two noticeable exceptions.
} 
host country and those who have arrived as children - perform at a significantly lower level with respect to mathematical literacy, reading literacy and scientific literacy than their native peers. As educational attainment is the main determinant of the socioeconomic position and the cultural integration, understanding the determinants of this achievement gap is a key challenge. Previous studies identify three main variables which are likely to influence specifically the educational achievement of children from foreign origin: educational attainment of parents, language spoken at home and age at immigration of the child.

As pointed out in Haveman and Wolfe (1995), the main determinant of the educational attainment of children is the educational attainment of their parents, especially the educational level of the mother. The PISA shows that in OECD countries, the parents of first-generation students and of second-generation students have generally completed fewer years of schooling than the parents of native students. Then, a first explanation of the educational gap between second-generation immigrants and their native-parentage peers could be that the parents of the first are on average less skilled than those of the second. Unfortunately, few studies intend to test precisely this linkage.

Following the seminal contribution of Chiswick (1988) and focusing on US data, Borjas (1995) finds a correlation between parental skills and the skills of children, but this correlation is not sufficiently high to remove ethnic skills differentials. This result is also confirmed by Card et alii (2000). Nevertheless, both studies are based on cross-sectional data that do not directly link the skills of a child with the skills of her own parents. They only exhibit correlation between the average skills of a cohort of immigrants and the average skills of a cohort of children of immigrants with respect to groups of different national origins.

Based on panel data relative to the Netherlands, Van Ours and Veenman (2003) show that there are no differences between the educational attainment of second-generation immigrants and natives, once age and parental education are controlled for. Then, according to this study, this is the difference between the educational level of the parents of the secondgeneration immigrants and the parents of the natives which explains the educational gap between immigrants and natives in the Netherlands. Departing from this result, Gang and Zimmermann (2000) conclude that parental schooling plays no role in the educational attainment of the children of foreign born in Germany, whereas it plays a major role in the educational attainment of the native parentage children.

These contrasting results suggest that the intergenerational transferability of skills may differ between natives and immigrants as well as between ethnic communities. In fact, several studies stress that the return to foreign experience and education is valued less than that 
obtained domestically (Chiswick and Miller, 1985, Kossoudji, 1989, Schaafsma and Sweetman, 2001). As long as immigrants would be unable to completely transfer the human capital accumulated in their home country to the labour market of the host country, it is also plausible that the impact of their skills on the educational attainment of their children depends on the place they have been acquired. Moreover, the adaptation level of the immigrants is likely to affect the intergenerational transmission of their human capital in the context of the host economy ${ }^{2}$. The return of the human capital of immigrants on the educational achievement of children is then likely to depend on the immigrants' place of schooling as well as their own age at immigration and their length of stay in the host country.

The second variable which is likely to have a specific effect on the educational achievement of children from foreign origin is the language spoken at home. Taking into account the educational and occupational status of parents, some contributions show that educational attainment is lower for young people who do not speak the language of the host country at home (Jones, 1987, Schaafsma and Sweetman, 2001). Nevertheless, to our knowledge, none paper directly evaluates the impact of the host-language proficiency of immigrants on the educational attainment of their offspring. Yet, Chiswick et alii (2004) show that there is a large positive correlation in the unmeasured determinants of proficiency between parents and children, after controlling for age, familial status and years of schooling. In this perspective, we aim at evaluating the impact of the French proficiency of immigrants on the educational attainment of their children as well as its impact on the returns of the other parental human capital covariates.

Thirdly, following the seminal paper of Jones (1987), Schaafsma and Sweetman (2001), Gonzales (2003), Chiswick and DebBurman (2004), Van Ours and Veenman (2006) and Böhlmark (2008) show that the place of birth and the age at arrival of children of immigrants affect their academic success. These studies conclude that children who arrived in their teenage years achieve a lower educational attainment than those who arrived in a very young age. Then, the ease of integration seems to be inversely related to age at immigration: the younger the age at immigration, the more easily the person adjusts to a new culture and curriculum. Bleakley and Chin (2004) and Newport (2002) also note that age at immigration influences the ability to acquire destination language skills because of the greater exposure to the destination language at school and the greater ability of youths to learn a new language. If

\footnotetext{
2 As notably pointed out by Portes and Rumbaut (1990) and Portes and MacLeod (1996), research on the sociology of immigration argue that the specific characteristics of the different immigrant communities such as their modes of incorporation in the host country play also a decisive role in their adaptation process which infers on the second generation's academic performance.
} 
the ease of acculturation depends on cultural differences between the origin country and the host country, it is likely that age at immigration will affect differently children from different origins. It is also possible that the return of the human capital of their parents on their educational attainment in the context of their host country depends on their age at arrival. The present contribution intends to address these different issues.

\section{Data and descriptive statistics}

\subsection{The Passage to Retirement of Immigrants survey}

We analyse the educational attainment of the second-generation of immigrants using French data from the Passage to Retirement of Immigrants survey (PRI hereafter) conducted by the Caisse Nationale d'Assurance Vieillesse and the Institut National de la Statistique et des Etudes Economiques from November 2002 to February 2003. The survey is representative of the different nationalities of the first-generation of immigrants living in France at the date of the survey and whose age is comprised between 45 and 70 .

Among other topics, the survey contains usual information on demographic and socioeconomic characteristics such as gender, age, familial status, education, financial status as well as work trajectories. It also contains original information on the migration history of the respondent such as economic status in country of origin, date of immigration and level of French proficiency. A unique feature of this survey is that it provides detailed information on the extended family of the respondent, including parents and children.

More precisely, for each child, we have information on gender, year of birth, country of birth, citizenship, current place and eventually year of arrival in France. The survey includes several additional questions only when the children are at least 16 years old ${ }^{3}$. In that case, we know whether each child is still enrolled in school or student as well as her highest level of diploma according to the following seven categories: 'no education', 'primary or secondary schooling', 'vocational school', 'high school', 'undergraduate studies', 'graduate studies', and 'postgraduate studies'.

The original sample of the survey includes 6211 families, with information on 19285 children. Among them, only $83.3 \%$ are at least 16 years old. Using the 'parent' sample, we then construct a 'child' sample where each child is counted as one observation. Since educational attainment is given only for those children who are at least 16 years old, we focus

\footnotetext{
${ }^{3}$ As this is a recollection date from the parents, then the data about the children may suffer from measurement errors. Controlling for unobserved heterogeneity using family effects (either random or fixed) allows reducing the underlying bias.
} 
in the sequel on the sample of children being 16 and older and also delete the few children with missing education (3303 observations deleted).

As older children have experienced very different educational conditions, we also drop from the sample children aged above 40 (1130 observations deleted). For the same reasons, we choose to exclude from the sample all the children who are not living in France at the date of the survey (1551 observations deleted) and those who arrived in France after 16 (1924 observations deleted). Finally, we focus on children with information on educational attainment of both the father and the mother (1551 observations deleted). These different selections leave us with a sample of 9866 children, corresponding to 4107 families.

A significant proportion of these children is currently enrolled at the date of the survey. The number of children who have completed their education is 6910 (70\%), while 2956 children $(30 \%)$ were still enrolled in 2003 . Since we do not observe by definition the completed level of education of the latter group of children, these are censored observations. In our empirical analysis, we essentially estimate the different regressions related to the educational attainment of the children of immigrants using the uncensored sample of 6910 parent-child pairs (3305 families). For the sake of robustness, we also present some regressions where we account for both uncensored and censored observations.

A main interest of the PRI survey is that we have for the selected subsample information on siblings. Both for the 'uncensored' and 'censored' samples, we report in Table 1 the number of families according to the number of children above 16 per family. About $74 \%$ of the respondents included in the uncensored sample have at most three children. The proportion is equal to $38.4 \%$ for parents with one child satisfying the selection criteria (16 and above, less than 40, living in France), 33.6\% for parents with two children, and $16.4 \%$ for parents with three children ${ }^{4}$.

\section{Insert Table 1 here}

Since there are multiple observations per family in many cases, we are able to control for unobserved heterogeneity at the family level through the use of family specific effects models. Actually, many unobserved factors associated with the child's educational attainment (like parental altruism or parental ability) are presumably highly correlated within siblings, meaning that estimates from standard regressions are likely to be biased ${ }^{5}$.

\footnotetext{
${ }^{4}$ The same proportions are respectively equal to $28.2 \%$ ( 1 child), $33.5 \%$ ( 2 children) and $20.9 \%$ (3 children) when considering the censored sample (see Table 1).

${ }^{5}$ In a recent contribution, Böhlmark (2008) also exploits within-family variation to study the role of age at immigration for the school performance gap between native and immigrant pupils in Sweden.
} 


\subsection{Descriptive statistics}

We present some descriptive statistics of the uncensored sample in Table 2, both for the parents and the second-generation children. Concerning the former, the distribution with respect to their country of origin reflects the French immigration pattern. The Southern Europe community (essentially made up by Portuguese, Spanish and Italian respondents) and the Northern African community (made up by Algerian, Moroccan and Tunisian migrants) represent more than $75 \%$ of the immigrant population living in France. Migrants from Asia and Turkey are much less numerous, though their fraction increases over time.

\section{Insert Table 2 here}

The sample shows important differences between communities with respect to skill. Female immigrants are generally less skilled than male immigrants. However, the differences in skill acquisition between female of two communities are rather similar to the ones between males of the same two communities. Immigrants coming from Northern Europe and America are relatively skilled. Many of them are graduated, while a very low fraction of this population has never been enrolled. On the opposite, very few Northern Africans are graduated and more than one third of this population has never been enrolled. The proportion of parents with no education is respectively $10 \%$ among the Middle Eastern community, but only 5\% among the Southern European population. Finally, the Asian community is more heterogeneous, since $40 \%$ of Asians are graduated and one quarter of them have no diploma.

With respect to French proficiency, nearly one fifth of Northern Europeans and Americans have difficulties in speaking or writing French, whereas quite half of Northern Africans are concerned. Comparing Asians and Southern Europeans, we note the particularly high fraction of Asians facing difficulties in French in spite of an education pattern close to the education pattern of the Southern Europeans. The younger mean age of arrival of Southern Europeans and their longer length of stay could contribute to explain their better proficiency in French.

Regarding the socioeconomic status of immigrants in their home country, Southern European and Northern African immigrants have a higher propensity to have grown up in a small town or a village as well as in a poor or a very poor financial context than other immigrants. These findings are of course related to differences in economic development among the various origin countries. Finally, we observe significant differences in the number of children. Whereas Northern Africans have on average three children above 16, Northern and Southern Europeans as well as Americans have less than two children. 
Concerning the children, significant differences appear between communities with respect to their educational attainment. Whereas more than $37 \%$ of children originated from Northern and Eastern Europe, America and Asia have completed more than high school education, this proportion reaches 31\% among Southern Europeans, 19\% among Northern Africans and 16\% among Middle Eastern children. Conversely, the proportion of children with no education or primary school is much higher in these ethnic groups. This proportion reaches 36\% when parents are from Northern Africa and $42 \%$ for other African or Middle Eastern populations, while the average rate for the whole sample of children is around $29 \%$.

For each origin group except America, the proportion of girls is lower than one half. For instance, it is equal to $46.5 \%$ and $45.8 \%$ when the parents originate from Southern Europe and Middle East respectively. As we only focus on children currently living in France, this difference in the gender composition is due to the fact that girls are more likely to live in the origin country ${ }^{6}$. On average, children from non-European countries are younger. Part of this age gap stems from differences in fertility rate, as parents from Africa, Middle Eastern and to a lesser extent from Asia have more children than other parents as well. The age pattern explains why children from Africa are more likely to be enrolled. Nevertheless, differences in enrolment rates are also due to the increased propensity for some groups to invest in the human capital of their children, which may explain the high rate observed among Asians.

Finally, when considering the place of birth, almost all children originating from Southern Europe are born in France, while more than the two thirds of children from Asian and Middle Eastern are foreign-born. Migratory legislations concerning free mobility area and the conditions under which immigrants have the right to have their family with them could partly explain these disparities ${ }^{7}$.

\section{Empirical analysis}

\subsection{Econometric strategy}

In what follows, we focus on the subsample of children who are not enrolled, i.e. the uncensored sample comprising 6910 children. As a significant proportion of these children

\footnotetext{
${ }^{6}$ When considering the whole sample of children (no restriction on age), $10.2 \%$ of girls are living in the origin country while the proportion is $9.1 \%$ for boys. As Dustmann (2003) points out, the welfare of the offspring perceived by the parent may vary depending on the location of the child. Concerns about preserving traditions may be more influent for female offspring than for male offspring.

${ }^{7}$ While there is a question about age at immigration in the PRI survey, there are unfortunately many missing observations. We then construct three categories for the age at immigration, i.e. 0-6 years, 7-11 years and 12-16 years, and define a dummy variable for the missing values. For the children not born in France, the missing category is around $11 \%$ of the whole sample, so that we mainly focus in our empirical analysis on the impact of being foreign-born on the educational attainment.
} 
did not complete schooling at the time of the survey, we extend our analysis and account for the censored observations in Subsection 4.3. Two main features of the PRI data have to be taken into account when attempting to explain educational attainment.

First, the survey provides an ordered categorical information for the level of schooling. Specifically, the pattern of diploma denoted by $e$ is defined as follows: 'no education' $(e=0)$, 'primary or secondary level' $(e=1)$, 'vocational studies' $(e=2)$, 'high school' ( $e=3)$, 'undergraduate studies' ( $e=4)$, 'graduate studies' $(e=5)$, and 'postgraduate studies' $(e=6)$. Let us assume that there exists a continuous latent variable $e^{*}$ for education, which we express as a function of a set of family characteristics $X$, a vector of coefficients $\beta$ and a residual $\varepsilon$ :

$$
e^{*}=X \beta+\varepsilon
$$

Given the various categories, we suppose that $e^{*} \leq \mu_{1}$ when $e=0, \mu_{1}<e^{*} \leq \mu_{2}$ when $e=1, \mu_{2}<e^{*} \leq \mu_{3}$ when $e=2, .$. , and $\mu_{6}<e^{*}$ when $e=6, \mu_{1}$ being normalized to 0 . Assuming that the random perturbation $\varepsilon$ is normally distributed, the corresponding model is a standard ordered Probit regression. The different parameters $\mu_{j}$ are a set of threshold levels which have to be estimated jointly with the vector of coefficients $\beta$.

The second concern with the data is that we have information on several children for many families. While siblings may be treated as independent observations, this assumption is clearly unlikely to hold. Indeed, as children from a given family have the same parents, their different educational levels are likely to be strongly correlated. Formally, this means that the model we seek to estimate should have the following form:

$$
e_{f i}^{*}=X_{f i} \beta+\delta_{f}+\varepsilon_{f i}
$$

where $f$ and $i$ refer respectively to the family and to the child. In (2), $\delta_{f}$ is an unobserved family effect. These family specific perturbations are supposed to be normally distributed, with mean 0 and variance $\sigma_{\delta}^{2}$. We assume that the disturbances $\varepsilon_{f i}$ follow a normal distribution, with mean 0 and variance $\sigma^{2}$, and that $X, \delta$ and $\varepsilon$ are independent. While the likelihood function for the above model involves multivariate normal integrals, one can rely on quadrature techniques to estimate the corresponding random effect ordered Probit model. The contribution to the final likelihood function is:

$$
\operatorname{Pr}\left(e_{i 1}, \ldots, e_{i N}\right)=\int_{-\infty}^{+\infty}\left[\Phi\left(\mu_{j+1}-X_{f i} \beta\right)-\Phi\left(\mu_{j}-X_{f i} \beta\right)\right] \phi\left(\delta_{f}\right) d \delta_{f}
$$


where $\phi\left(\delta_{f}\right)$ is the density of $N\left(0, \sigma_{\delta_{f}}^{2}\right)$. Two important remarks are in order. First, the different threshold levels $\mu_{j}$ are supposed to be constant across individuals. Second, by estimating a random effect model, we suppose that the unobserved family effects are uncorrelated with the covariates introduced into the regression. We relax this assumption in Subsection 4.3, where we also consider a fixed effect specification to explain the determinants of the second-generation educational attainment.

\subsection{Results from random effect ordered Probit regressions}

\section{Unconditional return of the parental education}

Let us first suppose that the return of the explanatory variables on the educational attainment of the second generation immigrants is independent of the migration history of their parents. We report in Table 3 econometric results from five random effect ordered Probit regressions estimated on the uncensored subsample (completed schooling). In column (1), we only control for the basic demographic characteristics of the child. The different covariates are gender, age (with four birth cohort dummies), number of siblings, number of sisters, birth order, place of birth and a dummy variables equal to one when the child was raised by both parents till 12. We also add into the regression a set of dummy variables related to the parental origin country (with six groups), Northern Europe, Eastern Europe and America being the reference.

\section{Insert Table 3 here}

As expected, the probability to report a higher level of education is higher for girls than for boys. With respect to older children (born before 1970), the level of education is respectively higher for those born between 1970 and 1979, but lower for those born after 1980. Among the younger cohorts, those who have left the educational system have on average a lower education. This is due to the fact that those who will achieve high levels of education have a higher propensity to be enrolled at the date of the survey. Concerning the family composition, the number of siblings and the rank of birth have a negative impact on the educational attainment, whereas the gender composition of the sibship (number of sisters) is weakly significant. As shown in Table 3, the family context matters since having been raised by both parents during youth significantly improves schooling.

We also find that the educational attainment is affected by the migration history of the child. According to the PRI survey, being foreign born has a strong negative impact on the educational attainment of the children. Very similar have been found among the second 
generation living in the Netherlands by Van Ours and Veenman $(2003)^{8}$. Finally, this first regression shows significant differences between origin communities with respect to the child's educational attainment. Southern European and Northern African children achieve a significantly lower level of education than Northern European, Eastern European and American children. The best performers originate from Asia, whereas the less ones originate from the Middle East.

As these community dummies may pick up permanent differences in parental characteristics, we then introduce the level of education of both the father and the mother along with the household income in the list of the covariates. From the corresponding results described in column (2) of Table 3, two key results appear. On the one hand, both the levels of education of the father and the mother have a large positive impact on the educational attainment of the child. The child's schooling is much higher when either the father or the mother have completed more than high school studies. However, it should be noted that there is no significant differences in the returns to paternal and maternal education ${ }^{9}$.

On the other hand, once the educational attainment of the parents is introduced in the regression, only two community effects differ from the others. The negative impact of being originated from the Middle East declines, but remains significant at the 5 percent level, whereas the positive impact of being originated from Asia is now higher. Hence, except for the Middle Eastern and Asian populations, the educational attainment of parents seems to capture the main roots of the educational gap of children between the migrants' communities. In the same way, the current level of household income significantly increases the child's level of education ${ }^{10}$.

In column (3), we introduce several additional variables dealing with the parental migration history. Both age at immigration of the parent and the length of stay in France when the child was 10 have a significantly positive impact on the educational attainment of the offspring. The parental proficiency in speaking French has also a large positive impact on the educational achievement of children. Clearly, these covariates can be considered as proxies for the assimilation level of the parent at a crucial moment of the child's education. A last

\footnotetext{
${ }^{8}$ However, with respect to these authors, we did not find significant differences for the various categories of age at immigration. With respect to the reference category (being born in France), the coefficients for the 0-6 years, 7-11 years and 12-16 years groups are not significantly different. These additional results are available upon request from the authors.

${ }^{9}$ When testing the hypothesis of equal returns, we find a value of 3.53 for the test (with four degrees of freedom), which is not significant at conventional levels.

${ }^{10}$ Also, it should be noted that controlling for parental schooling and household income does not really affect the magnitude of the estimates related to the child characteristics.
} 
finding is that having poor parents during childhood reduces the educational attainment of the second generation.

This extended specification brings to the fore two main results. First, as expected, the parental migration significantly influences the educational potential of the children in the context of host country. Notably, tacking into account language proficiency and length of stay in the host country lowers the disadvantage of being originated from the Middle East, which is no longer significant. Concerning this last point, the estimation of separated models for boys and girls is enlightening. As shown in columns (4) and (5) of Table 3, the origin effect related to Middle Eastern is negative, but it is only significant among daughters. Secondly, the introduction of covariates reflecting the degree of assimilation of immigrants lowers the impact of the parental level of schooling on the educational achievement of the offspring. The educational level of immigrants then characterizes their growth educational potential, but also their ability to transfer it to their children in the context of the host country.

To sum up, the familial human capital background explains the main part of educational attainment gaps between communities in France. Nevertheless, we show that for second generation immigrants, the degree of assimilation of their parents in the host country, characterised notably by their host country language fluency or their length of residence, is also a fundamental component of their familial human capital background.

\section{Conditional return of parental human capital}

In the previous specifications, the return of parental skills on the educational attainment of their child was supposed to be independent of their migration history ${ }^{11}$. However, this return is notably likely to depend on where they have been educated themselves. Educational systems differ between countries and some educational systems can be more efficient than others. Then, the return of education in the host country should be lower for immigrants coming from countries with less efficient systems. Moreover, the transferability of skill between countries can depend on the proximity between their education systems and on the ability of immigrant to transfer their skill to their child in the context of host country. As suggested by model (3) in Table 3, this ability of transfer is likely to depend on their degree of assimilation characterised notably by their host language fluency or their length of stay in the host country.

\footnotetext{
${ }^{11}$ Chiswick and Miller (1985), Kossoudji (1989), Schaafsma and Sweetman (2001) point notably that the return to foreign experience and education on the labour market is valued less than that obtained domestically.
} 
To investigate these issues, we first convert the highest qualification of the parent into years of schooling. Note that we restrict our attention to the situation of the household head, as the PRI questionnaire does not allow us to make a distinction between years of education completed in the origin country and years of education completed in France for both parents. In model (1) of Table 4, we present the results of the basic specification with the parental years of schooling instead of the ordered levels of educational attainment. We again find evidence of a (strongly) significant positive effect of the parental education. Furthermore, the other estimates are rather similar to those described in model (3) of Table $3^{12}$.

\section{Insert Table 4 here}

We then estimate a model where the number of years of schooling is interacted with the country of origin of the parent. Model (2) in Table 4 leads to the following conclusions. First, the return to the parental education is significantly lower when the parent is originated from North Africa. Second, tacking into account the potential interaction between the return to education and the country of origin of the parent lowers the residual impact of the country of origin. Then, we can argue that the origin of immigrants affects the return of their education on the educational attainment of their child in the context of the host country.

To test whether the degree of assimilation of immigrant affects their ability to transfer their skill to their child in the host country, we take into account potential interaction between years of schooling and French proficiency in model (3). Our results are twofold. First, the return of parental education on the educational attainment of the child is clearly lower when the parent faces difficulties in speaking French. Then, host language proficiency facilitates the transfer of skill from immigrants to their children. Second, the crossed terms significantly lower the return of the parental education for Middle Eastern immigrants, whereas it increases the return of the parental education for Asian immigrants. Hence, one can argue that for a given level of French proficiency, Asian immigrants have a comparative advantage when transferring their skill to their children whereas Middle Eastern immigrants have a comparative disadvantage.

Finally, we tack into account the age at immigration of the parent and decompose years of schooling into years of schooling in the origin country and years of schooling in France. Model (4) of Table 4 shows that the return of years of schooling in the origin country

\footnotetext{
${ }^{12}$ With respect to the model (3) in Table 3 which includes four dummy variables related to parental education, we find some differences concerning the origin country dummies. In particular, the effect is negative when parents originate from Southern Europe (at the 5\% level) and from Northern Africa (at the $10 \%$ level), Northern and Eastern Europe being the reference category. Nevertheless, the most important estimates are the negative coefficient of the Middle origin and the positive coefficient of the Asian origin.
} 
is slightly lower than the return of years of schooling in France. However, the difference between the two coefficients is not significant at conventional level. We have also introduced crossed effects between the place of schooling and the French proficiency level. These additional results, not reported, indicate that difficulties in speaking French have a particular detrimental effect on the return of foreign education for North Africans.

\subsection{Robustness issues}

Censoring. So far, we have only considered children older than 16 who were having completed their education at the time of the survey. Nevertheless, as shown in Table 2, the proportion of enrolled children clearly depends on origin country. On average, $30 \%$ of children have not yet completed schooling at the time of the survey. Whereas less than $17 \%$ of children originating from Southern Europe are enrolled, this proportion exceeds $50 \%$ for children originating from Southern Africa or America. These differences in enrolment rates between communities are likely to bias our estimates. If enrolled children achieve finally on average a higher level of education than children having completed schooling, then regressions based on the censored sample would underestimate the educational attainment of children from communities with high enrolment rates.

To investigate this issue, we extend our previous analysis by treating enrolled children as censored $^{13}$. For the presentation, let $c$ be a dummy variable equal to one when education is completed (uncensored observation), and to zero otherwise (censored observation). For a given outcome $j, \operatorname{Pr}(e=j)$ is given by $\operatorname{Pr}(e=j)=\Phi\left(\mu_{j+1}-X_{f i} \beta\right)-\Phi\left(\mu_{j}-X_{f i} \beta\right)$ when the child is not at school, while the probability is $\operatorname{Pr}(e=j)=1-\Phi\left(\mu_{j}-X_{f i} \beta\right)$ under censoring. So, in the general case, we get the following expression for a given level of education:

$$
\operatorname{Pr}(e=j)=c *\left(\Phi\left(\mu_{j+1}-X_{f i} \beta\right)-\Phi\left(\mu_{j}-X_{f i} \beta\right)\right)+(1-c) *\left(1-\Phi\left(\mu_{j}-X_{f i} \beta\right)\right)
$$

Since there are repeated observations within the family, we can further control for unobserved heterogeneity at the family level. With $\delta_{f}$ the specific family component, the contribution to the final likelihood function max be expressed as $\operatorname{Pr}\left(e_{i 1}, \ldots, e_{i N}\right)=\int_{-\infty}^{+\infty} \operatorname{Pr}(e=j) \phi\left(\delta_{f}\right) d \delta_{f}$. Again, this random effect ordered Probit model with censoring can be estimated using a maximum likelihood method and quadrature techniques.

\footnotetext{
${ }^{13}$ Picard and Wolff (2008) also estimate random effects ordered Probit models with both uncensored and censored observations to explain inequalities between and within families in Albania.
} 
The corresponding estimates are in Column (1) of Table 5. We find that accounting for censoring does not affect the impact of the most influential covariates on the child's level of schooling. Educational attainment is lower when the child has several siblings, is foreign born and was not raised by both parents during youth. Conversely, it is higher when the parents are high educated and have no difficulty in speaking French and it increases with the household current level of income and the respondent's age at immigration. There are also differences in the role of origin country, with a lower level of education among the Middle Eastern group and a higher level among the Asian group ${ }^{14}$.

\section{Insert Table 5 here}

However, once the sample includes uncensored and censored observations, we observe two differences for the following explanatory variables. First, as shown in Column (1) of Table 5, the educational attainment is on average higher for all the cohorts born after 1970, while the coefficient was negative for the cohorts born after 1980 in Column (1) of Table 3. This was due to a selection bias, since more "efficient" children who were still enrolled in higher level studies were not considered in the uncensored regression. So, our results on the more recent cohorts confirm the increasing trend in length of studies. Secondly, censoring affects the impact of gender, whose effect on education is now significantly higher. This is due to the fact that girls are more frequently enrolled according to the PRI survey, with enrolment rates of $27.4 \%$ among boys and $32.8 \%$ among girls.

Fixed effects. A shortcoming of the random effect specification is that the family unobserved components are supposed to be uncorrelated with the individual characteristics. We now relax this exogeneity assumption and estimate a fixed effect ordered Probit model. While this model can be estimated by a classical minimum distance estimator method, we choose to rely on a maximum likelihood method. As shown in Greene (2004), the fixed effect ordered model can be estimated by 'brute force' taking advantage of the properties of the sparse second derivatives matrix. While there is no covariance matrix computed for the fixed effects, the unconditional log method is maximizing by using Newton's method ${ }^{15}$.

As usual in such models, we have to drop from the regression all the covariates which remain constant at the family level. For instance, parental education cannot be controlled for

\footnotetext{
${ }^{14}$ As shown in Columns (2) and (3) of Table 5, very similar results are found when estimating separate regressions for boys and girls, although we note that the negative effect observed for the Middle Eastern group is only significant among girls. A similar pattern was found when using the uncensored sample.

${ }^{15}$ The Hessian of the fixed effects ordered model may be expressed as a 'within groups' moment matrix. See Grenee (2004, section 2) for further details of the full maximum likelihood estimation. The fixed effects regressions were estimated using the Limdep software.
} 
in a fixed effect regression since there is no variability at the family level for that covariate. The impact of the parental characteristics and of the number of siblings is in fact picked up by the family fixed effect, and only characteristics of the child are controlled for in the fixed effect specification. Furthermore, we restrict our attention to the sample of children who have completed their schooling at the time of the survey.

Results from the fixed effect regression are in Column (4) of Table 5.With respect to the random effect specifications, we reach slightly different conclusions. First, we still find a negative coefficient on schooling when the child is born in a foreign country, but this effect is no longer significant. Secondly, the presence of both parents during childhood still has a positive effect, although it is now hardly significant (at the 10 percent level). Finally, it matters to estimate separate regressions respectively for boys and girls. While the level of education is higher for the youngest cohort (born after 1980) among boys, the reverse pattern holds among daughters. Also, the negative effect of the rank within the sibship holds only for boys, while having been raised by both parents during youth is only beneficial for girls.

So, these results from fixed effect ordered models show that the role of the child's characteristics strongly depends on whether the family components are supposed to be uncorrelated to the individual characteristics or not. This is really a crucial issue, especially when considering the effect of being foreign born on educational attainment.

\section{Conclusion}

In this paper, we have investigated the determinants of the educational attainment of the second-generation of immigrants living in France. Our regressions control for unobserved heterogeneity at the family level and account for censoring of enrolled children. Our main finding is that the skill of immigrants explains the main part of the ethnic educational gaps between their children. Nevertheless, the assimilation degree of immigrants, essentially captured by their French fluency or their length of stay in their host country, also contributes to explain a part of the ethnic educational gaps between their children. Furthermore, the return of the educational attainment of immigrants on the educational attainment of their children depends on their place of origin, their place of schooling as well as their French proficiency.

When comparing the different ethnic groups, we find that the educational attainment is lower among children of Middle East origin. Also, the return to the parental education is lower when parents are from North Africa. From a public policy viewpoint, this suggests that it could be useful to promote special educational programs in favor of these disadvantaged groups At the same time, it would be of interest to further understand why some parents tend 
to under-invest in the human capital of their children. If for instance parents choose to invest less in the education of their children because they expect their children to be discriminated on the labor market, then anti-discriminatory policies encouraging anonymous applications would be effective in narrowing the educational gaps among children of different origins.

A final comment is that we have only focused on the educational attainment of the second-generation of immigrants in this paper. This is due to the fact that the PRI survey only includes respondents of foreign origin. In France, it would be useful to further compare not only educational outcomes, but also employment and earnings of both the second-generation immigrants in France and natives. We leave this task for future research. 


\section{References}

Becker G., Tomes N., 1986. "Human capital and the rise and fall of families", Journal of Labor Economics, 4 (S1-S39).

Behrman J., 1997. "Intrahousehold distribution and the family", in Rosenzweig M.R., Stark O., eds, Handbook of Population and Family Economics, North-Holland, Elsevier (125187).

Bleakley H., Chin A., 2004. "Language skills and earnings: Evidence from childhood immigrants", Review of Economics and Statistics, 86 (481-496).

Böhlmark A., 2008. "Age at immigration and school performance: A siblings analysis using Swedish register data", Labour Economics, 15 (1366-1387).

Borjas G., 1995. "Ethnicity, neighbourhoods, and human capital externalities", American Economic Review, 85 (365-390).

Card D., DiNardo J., Estes E., 1998. "The more things change: Immigrants and children of immigrants in the 1940s, the 1970s, and the 1990s", NBER Working Paper, 6519.

Chiswick B., 1988. "Differences in education and earnings across racial and ethnic groups: tastes, discrimination, and investment in child quality", Quarterly Journal of Economics, 103 (571-597).

Chiswick B., DebBurman N., 2004. "Educational attainment: Analysis by immigrant generation”, Economics of Education Review, 23 (361-379).

Chiswick B., Miller P., 1985. "Immigrant generation and income in Australia", Economic Record, 61 (540-553).

Coate S., Loury G., 1993. "Will affirmative-action policies eliminate negative stereotypes ?", American Economic Review, 83 (1220-1240).

Dustmann C., 2003. "Children and return migration", Journal of Population Economics, 16 (815-830).

Gang I., Zimmermann K., 2000. "Is child like parent ? Educational attainment and ethnic origin", Journal of Human Resources, 35 (550-569).

Garg A., Morduch J., 1998. "Sibling rivalry and the gender gap: Evidence from child health outcomes in Ghana", Journal of Population Economics, 11 (471-493).

Gonzalez A., 2003. "The education and wage of immigrant children: The impact of age at arrival", Economics of Education Review, 22 (203-212).

Greene W.H., (2004), "The behavior of the fixed effect estimator in nonlinear models", Econometrics Journal, vol. 7, pp. 98-119.

Haveman R., Wolfe B., 1995. "The determinants of children's attainments: A review of methods and findings", Journal of Economic Literature, 4 (1829-1878).

Jones F., 1987. "Age at immigration and education: Further implications", International Migration Review, 21 (70-85).

Kossoudji S., 1989. "Immigrant workers assimilation: Is it a labour market phenomenon ?", Journal of Human Resources, 24 (494-527).

Lainé F., Okba M., 2005. "L'insertion des jeunes issus de l'immigration: De l'école au métier", Collection Net-Doc du CEREQ, 15. 
Losen D., Orfield G., 2002. Minority Issues in Special Education, The civil rights project at Harvard University and Harvard Education Press, Cambridge.

Morduch J., 2000. "Sibling rivalry in Africa", American Economic Review, 90 (405-409).

Newport E., 2002. "Critical periods in language development", in Nadel L., ed, Encyclopedia of Cognitive Science, Mac-Millan Publishing, London.

OECD, 2006. Where immigrant students succeed. A comparative review of performance and engagement in PISA 2003.

Ono H., 2004. "Are sons and daughters substituable ? Allocation of family resources", Journal of the Japanese and International Economy, 18 (143-160).

Picard N., Wolff F.C., 2008. "Measuring educational inequalities: Evidence from Albania", Journal of Population Economics, forthcoming.

Portes A., Rumbaut R., 1990. Immigrant America: A portrait, Berkeley: University of California Press.

Portes A., MacLeod D., 1996. "Educational progress of children of immigrants: The roles of class, ethnicity and school context", Sociology of Education, 69 (255-275).

Schaafsma J., Sweetman A., 2001. "Immigrants earnings: Age at migration matters", Canadian Journal of Economics, 34 (1066-1099).

Thomas D., 1994. "Like father, like son: Like mother, like daughter. Parental resources and child height", Journal of Human Resources, 29 (950-988).

Thomas D., Schoeni R.F., Strauss J., 1996. "Parental investments in schooling: The roles of gender and resources in urban Brazil", Mimeo, Rand Labor and Population Program.

Van Ours J., Veenman J., 2006. "Age at immigration and educational attainment of young immigrants", Economics Letters, 90 (310-316).

Van Ours J., Veenman J., 2003. "The educational attainment of second generation immigrants in Netherlands", Journal of Population Economics, 35 (550-569). 
Figure 1. Distribution of educational attainment of the second generation

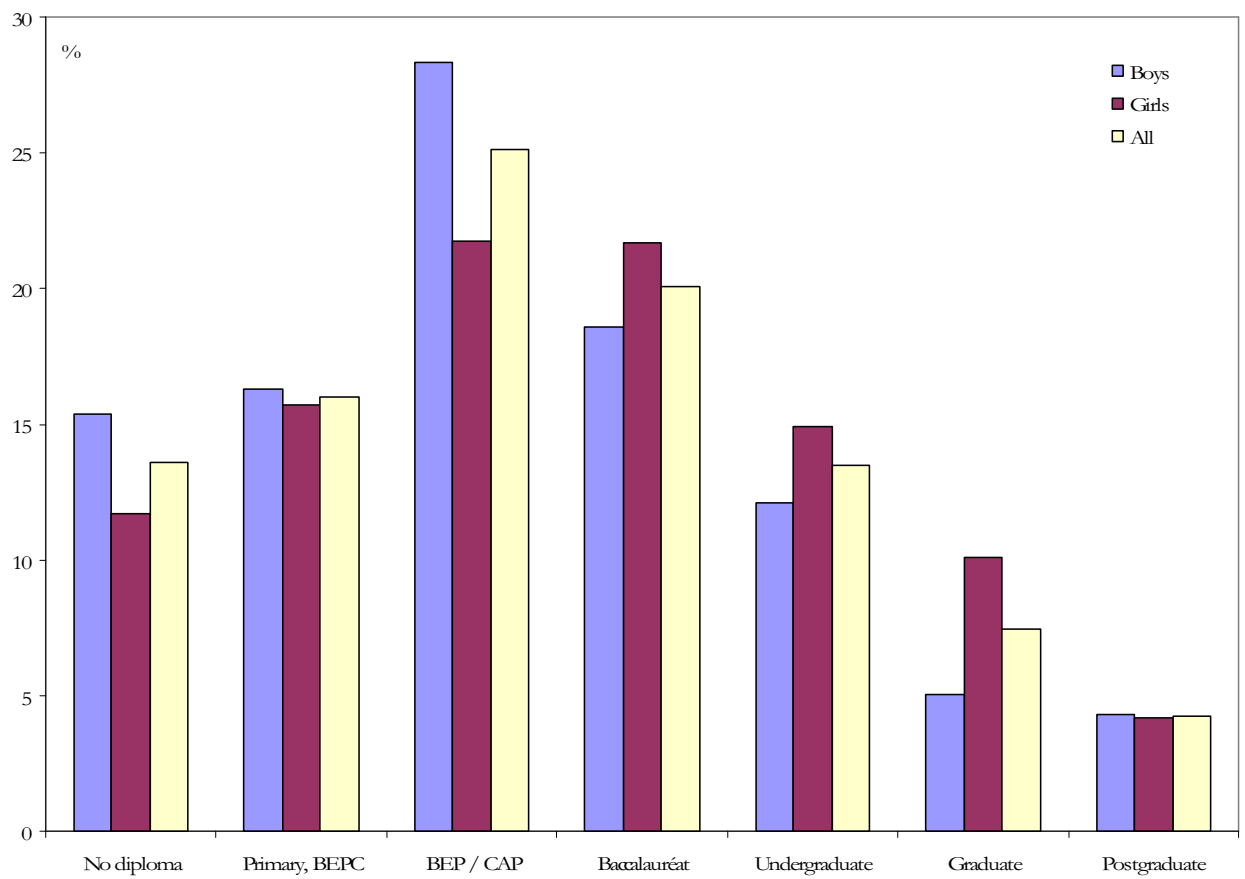

Source: survey PRI 2003. 
Table 1. Description of the sample

\begin{tabular}{|l|c|c|c|c|}
\hline \multirow{2}{*}{$\begin{array}{l}\text { Number of children above } 16 \\
\text { per family }\end{array}$} & \multicolumn{2}{|c|}{ Censored sample } & \multicolumn{2}{c|}{ Uncensored sample } \\
\cline { 2 - 5 } & Number of families & Number of children & Number of families & Number of children \\
\hline 1 & 1270 & 1270 & 1160 & 1160 \\
3 & 1111 & 2222 & 1375 & 2750 \\
4 & 545 & 1635 & 858 & 2574 \\
5 & 222 & 888 & 405 & 1620 \\
6 & 83 & 415 & 176 & 880 \\
7 & 47 & 282 & 75 & 450 \\
8 & 19 & 133 & 37 & 259 \\
9 & 7 & 56 & 16 & 128 \\
\hline Total & 1 & 9 & 5 & 45 \\
\hline
\end{tabular}

Source: survey PRI 2003. 
Table 3. Random effect ordered Probit estimates of the child's educational attainment

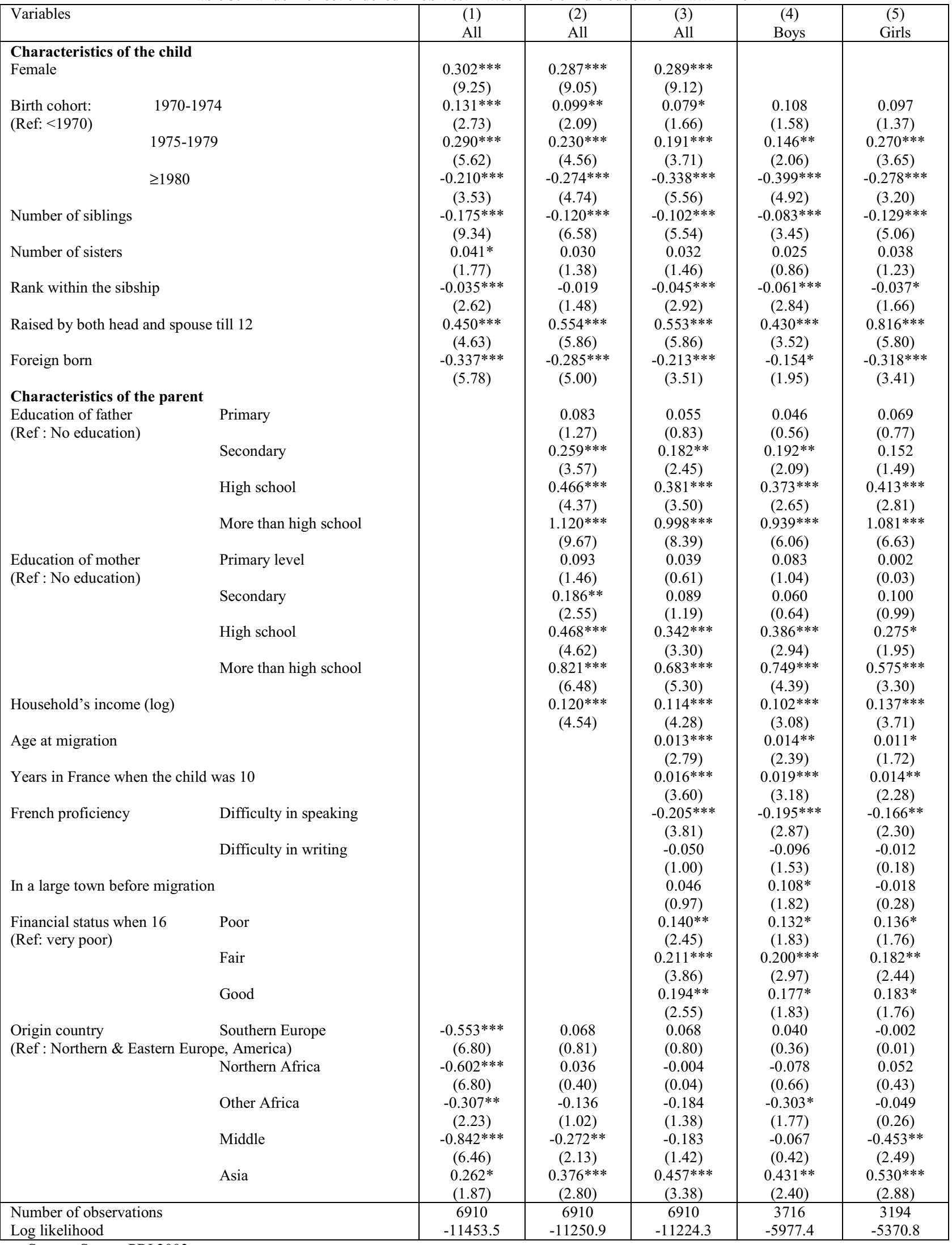

Source: Survey PRI 2003.

Note: Estimates from random effect ordered Probit. The different regressions also include a set of threshold values. Absolute values of tstatistics are in parentheses and levels of significance are respectively $1 \%(* * *), 5 \%(* *)$ and $10 \%(*)$. 
Table 4. Random effect ordered Probit estimates of the child's educational attainment, with crossed effects

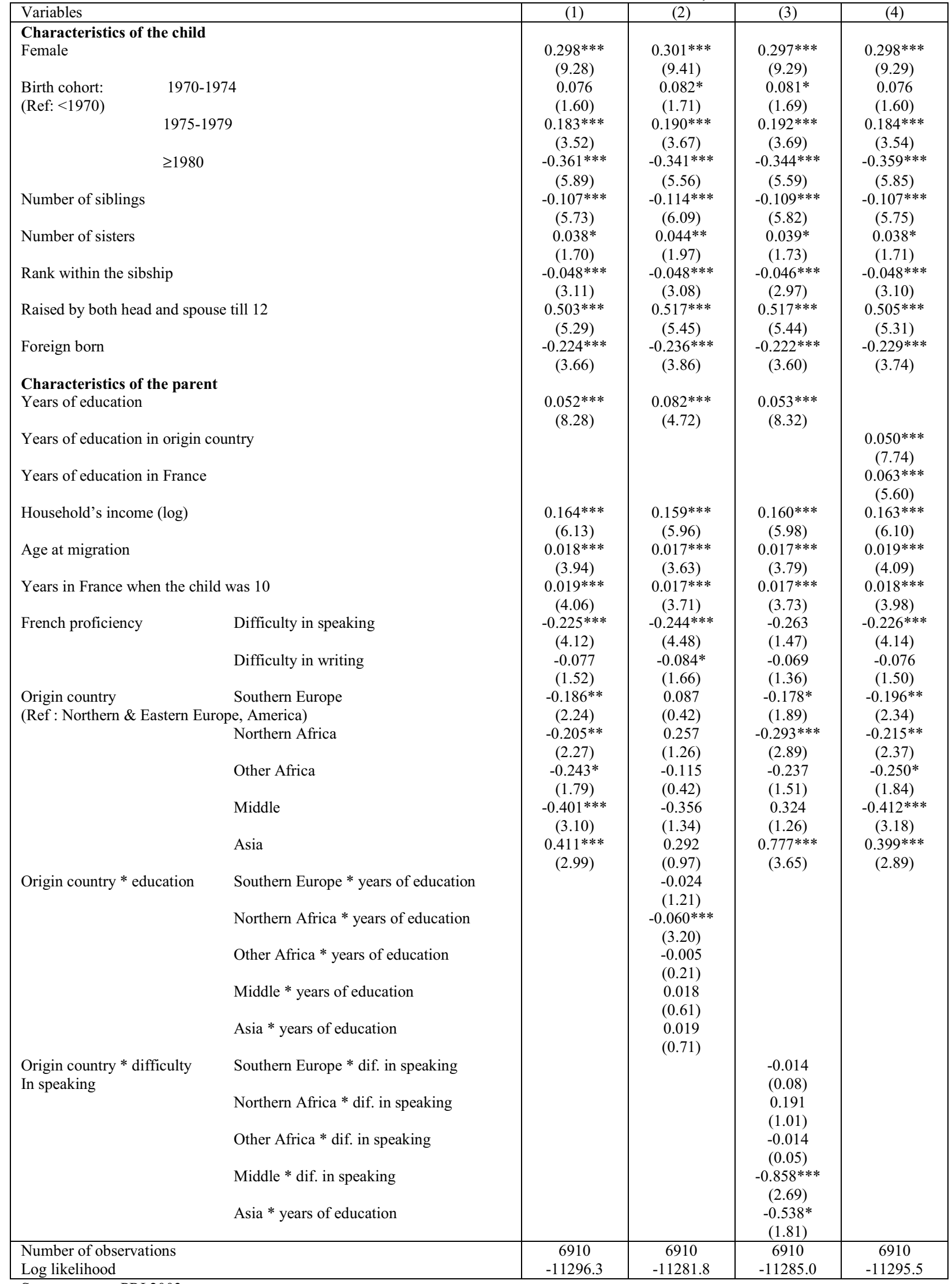

Source: survey PRI 2003.

Note: Estimates from random effect ordered Probit. The different regressions also include a set of threshold values. Absolute values of tstatistics are in parentheses and levels of significance are respectively $1 \%(* * *), 5 \%(* *)$ and $10 \%(*)$. All these models also control for whether parents were living in a large town before migration and parental financial status when 16 . 
Table 5. Random effect censored and fixed effect ordered Probit estimates of the child's educational attainment

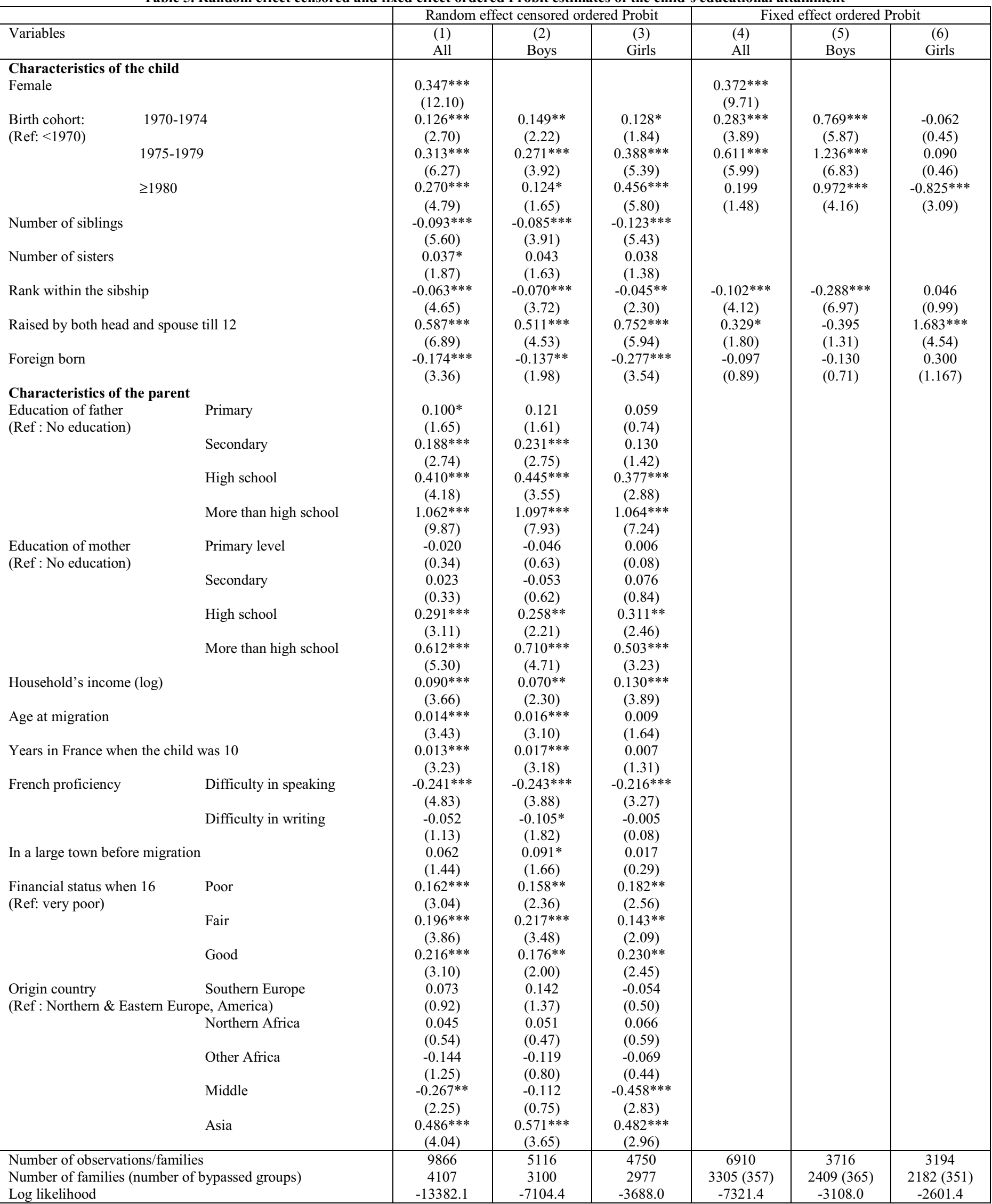

Source: Survey PRI 2003.

Note: Estimates from random effect censored ordered Probit and fixed effect ordered Probit. The random effect regressions also include a set of threshold values. Absolute values of t-statistics are in parentheses and levels of significance are respectively $1 \%(* * *), 5 \%(* *)$ and $10 \%(*)$. 